Www.jmscr.igmpublication.org

Impact Factor (SJIF): 6.379

Index Copernicus Value: 79.54

ISSN (e)-2347-176x ISSN (p) 2455-0450

crossrefDOI: https://dx.doi.org/10.18535/jmscr/v6i12.174

Journal Of Medical Science And Clinical Research

IGM Publication

An Official Publication of IGM Publication

\title{
The Clinical Outcomes of Local Steroid Injection Plus Conservative Management and Conservative Management Alone in Chronic Low Back Pain Due to Myofascial Pain Syndrome
}

\author{
Authors \\ Dr Bisha Babu ${ }^{1}$, Dr Sreejith Kalathummarath ${ }^{2}$, Dr Sreedevi Menon $\mathbf{P}^{3}$ \\ ${ }^{1}$ Senior Resident, Govt medical College, Kottayam \\ ${ }^{2}$ Associate Professor, Govt Medical College, Kottayam \\ ${ }^{3}$ Profossor, Govt Medical College Kozhikode \\ Corresponding Author \\ Dr Sreejith Kalathummarath \\ Associate Professor, Govt Medical College Kottayam, Kerala, India \\ Email:Sreejithpmr@gmail.com
}

\begin{abstract}
Background: Myofascial Pain Syndrome (MPS) is defined as a regional pain syndrome characterised by muscle pain caused by myofascial trigger points (MTrPs). The prevalence of MPS among chronic back pain patients is high. Clinical features are exquisite spot tenderness, pain recognition, taut band, referred pain and local twitch response. Treatment includes both conservative and invasive type. There was no obvious study to assess the effectiveness of steroid infiltration in myofascial pain syndrome when compared to conservative management. So aim of the study was to compare the pain and functional outcomes of local steroid injection and conservative management and conservative management alone in chronic low back pain due to Myofascial Pain Syndrome.

Methods: This prospective comparative study was conducted in Department of Physical Medicine and Rehabilitation, Government Medical College Kozhikode. Duration of study was one year and consisted of a sample size of 60. Study started with collection of information regarding demographic factors and randomly giving the treatment to the groups. Patients were followed up at $3^{\text {rd }}$ week. Outcome measures were Visual Analogue Scale and Short Form Mcgill Pain Questionnaire for pain and Oswestry Low Back Pain and Disability Index for functional outcome and Case record form.

Results: When pain scores were measured by the SF McGill Pain Questionnaire and by the VAS, steroid infiltration combined with conservative management showed better results than those in the conservative management group at the follow-up visit, the scores being statistically significant.

Conclusion: In this study it was found that local steroid injection of Myofascial Trigger Points combined with conservative management resulted in better pain relief and functional outcome in chronic low back pain due to Myofascial Pain Syndrome than conservative management alone.
\end{abstract}

\section{Introduction}

Myofascial Pain Syndrome (MPS) is defined as a regional pain syndrome characterised by muscle pain caused by myofascial trigger points $(\mathrm{MTrPs})^{1}$. Trigger points are commonly found in the trapezius, levator scapulae, infraspinatus, 
gluteal, tensor fascia lata, quadrates lumborum and gastrocnemius muscles. The prevalence of MPS among chronic back pain patients was $63.5 \%(\mathrm{n}=80)^{2}$. Clinical features are exquisite spot tenderness, pain recognition, taut band ,referred pain and local twitch response ${ }^{1,3}$. Treatment includes both conservative and invasive type. The conservative treatment includes intermittent cold and stretch, deep pressure soft tissue massage, trigger point pressure release and postisometric relaxation ${ }^{4}$.Invasive trigger point therapy can be divided into dry needling and injection (steroid) into trigger points.. Malanga $G$ et al reported that trigger point injection or dry needling doesn't show improvement with a trial of conservative noninvasive therapy in myofascial pain $^{5}$. The current recommendation is to use $0.25 \%$ lidocaine, which is more effective than stronger concentrations ${ }^{6}$. Xie $\mathrm{P}$ et al reported that lidocaine-injection therapy in the intramuscular innervation zone significantly reduced the degree and frequency of neck pain in patients at 6 months after treatment ${ }^{7}$. There is no scientific evidence for injections with steroids, vitamin B12,non steroidal anti-inflammatories and bee venom ${ }^{8}$. Mata Diz JB et $\mathrm{al}^{9}$ reported that exercise has positive small-to-moderate effects on pain intensity at short-term follow-up in people with myofascial pain. A combination of stretching and strengthening exercises seems to achieve greater effects.

Clara S M Wong et $\mathrm{al}^{10}$ mentioned that the mechanism of action of trigger point injections is thought to be disruption of the trigger points by the mechanical effect of the needle or the chemical effect of the agents injected, resulting in relaxation and lengthening of the muscle fibre. The effect of the injectate may include local vasodilation, dilution, and removal of the accumulated nociceptive substrates.

According to Niraj $\mathrm{G}^{11}$, trigger point injection with local anesthetic was useful in diagnosis but ineffective in providing durable relief. But trigger point injection with steroids and pulsed radiofrequency treatment of trigger point(s) were effective. There was improvement reported in painintensity scores, quality of life, anxiety, and depression scores following the interventional management of abdominal myofascial pain syndrome. There was no obvious study to assess the effectiveness of steroid infiltration in myofascial pain syndrome when compared to conservative management. So aim of the study was to compare the pain and functional outcomes of local steroid injection and conservative management and conservative management alone in chronic low back pain due to Myofascial Pain Syndrome.

\section{Methodology}

Study Design: Comparative study with pretext and post text design

Study Setting: Department of Physical Medicine and Rehabilitation, Government Medical College, Kozhikode, Kerala, India

Study Period: APRIL 2014 to March 2015

Study Population: Patients with chronic low back pain due to Myofascial Pain Syndrome, attending the Department of Physical Medicine and Rehabilitation of Government Medical College, Kozhikode, Kerala, India.

\section{Inclusion Criteria}

1. Patients presenting with chronic low back pain due to Myofascial Pain Syndrome

2. Patients in the age group $18-75$ years

3. Either sex

\section{Exclusion Criteria}

1. Patients not giving consent

2. Pregnant and nursing mothers

3. Patients with cognitive problems

4. Patients with neurological deficit

5. Patients with neurogenic claudication

6. Patients with peripheral occlusive vascular disease

7. Patients with uncontrolled diabetes mellitus

8. Patients with recent $\mathrm{h} / \mathrm{o}$ myocardial infarction

9. Patients with connective tissue diseases and myopathies

10. Patients with severe osteoporosis and severe deformities of spine 
68 patients were selected as per the inclusion and exclusion criteria. Out of them 5 declined participation and 3 were excluded. After getting informed consent, the remaining 60 patients were subjected to detailed history and clinical examination. Clinical examination includes provocative tests and detailed neurological examination to rule out the diseases mentioned in exclusion criteria. If found necessary, the patients were advised to undergo laboratory investigations and imagimg to rule out co morbidities.

Patients were allocated to one of the two groups through block randomisation by satisfying the inclusion and exclusion criteria.

Patients were divided into two groups. Each group consisted of 30 patients. Group A was advised conservative management alone and group B was treated with steroid infiltration and also advised conservative management. The patients in both groups were instructed in the appropriate stretching and strengthening exercises, optimal postural adjustments and principles of back hygiene. These instructions being oriented to health and well-being, was advised to be followed for a life-time.

Outcome measures were Visual Analogue Scale, Short Form Mcgill Pain Questionnaire for pain and Oswestry Low Back Pain and Disability Index for functional outcome and Case record form. Measurements were taken before and after 3 weeks of intervention. All outcome measures VAS, ODI, MC gill questionaire are ordinal scales so we used non parametric tests.

\section{Ethical Clearance}

Ethical clearance was obtained from the Institutional Human Ethics Committee on 02-012014. Confidentiality and anonymity of the patient's information were maintained during and after the study.

\section{Data Analysis}

Data analysis was performed by SPSS (version 17) for windows. Alpha value was set as 0.05 . Descriptive statistics was performed to find out mean, standard deviation for the demographic variable and outcome variables. Mann whitney U test was used to find out difference in scores between groups for VAS, Mc Gill \& ODI at Baseline and post measurement. Wilcoxon signed rank sum test was used to find out significant difference with in group for VAS, Mc Gill \& ODI. Microsoft excel, word was used to generate graph and tables.

\section{Results}

Table I: Baseline data for demographic and outcome variable

\begin{tabular}{|l|c|c|c|c|}
\hline Sl. No: & Variables & Group A(conservative) & Group B(steroid) & P-value \\
\hline 1 & Age & $42.40 \pm 10.09$ & $39.60 \pm 12.09$ & $>0.334$ \\
\hline 2 & Mc.Gill & $13.75 \pm 1.43$ & $13.45 \pm 1.53$ & $>0.510$ \\
\hline 3 & VAS & $7.98 \pm 0.72$ & $7.82 \pm 0.56$ & $>0.254$ \\
\hline 4 & ODI & $36.30 \pm 10.56$ & $36.87 \pm 8.13$ & $>0.730$ \\
\hline
\end{tabular}

Table II: Pre -post data within group A

\begin{tabular}{|l|c|c|c|c|}
\hline Sl. No: & Variables & Pre & Post & P-value \\
\hline 1 & Mc.Gill & $13.75 \pm 1.43$ & $13.43 \pm 1.49$ & $>0.075$ \\
\hline 2 & VAS & $7.98 \pm 0.72$ & $7.66 \pm 0.75$ & $<0.001$ \\
\hline 3 & ODI & $36.30 \pm 10.56$ & $31.60 \pm 8.95$ & $<0.0001$ \\
\hline
\end{tabular}

Table III: Pre -post data within group B

\begin{tabular}{|l|c|c|c|c|}
\hline Sl. No: & Variables & Pre & Post & P-value \\
\hline 1 & Mc.Gill & $13.45 \pm 1.53$ & $9.46 \pm 3.09$ & $<0.0001$ \\
\hline 2 & VAS & $7.82 \pm 0.56$ & $5.86 \pm 1.53$ & $<0.0001$ \\
\hline 3 & ODI & $36.87 \pm 8.13$ & $17.83 \pm 11.73$ & $<0.0001$ \\
\hline
\end{tabular}


Table IV: Difference between groups

\begin{tabular}{|l|c|c|c|c|}
\hline Sl. No: & Variables & Group A(conservative) & Group B(steroid) & P-value \\
\hline 1 & Mc.Gill & $13.43 \pm 1.49$ & $9.46 \pm 3.09$ & $<0.0001$ \\
\hline 2 & VAS & $7.66 \pm 0.75$ & $5.86 \pm 1.53$ & $<0.0001$ \\
\hline 3 & ODI & $31.60 \pm 8.95$ & $17.83 \pm 11.73$ & $<0.0001$ \\
\hline
\end{tabular}

Graph I: Mean Mc Gill among both groups

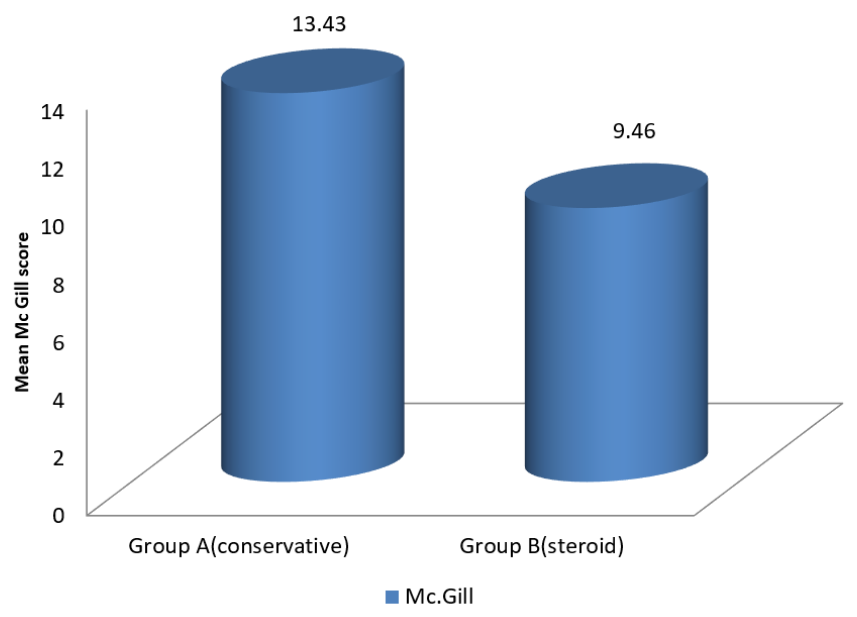

Graph II: Mean VAS among both groups

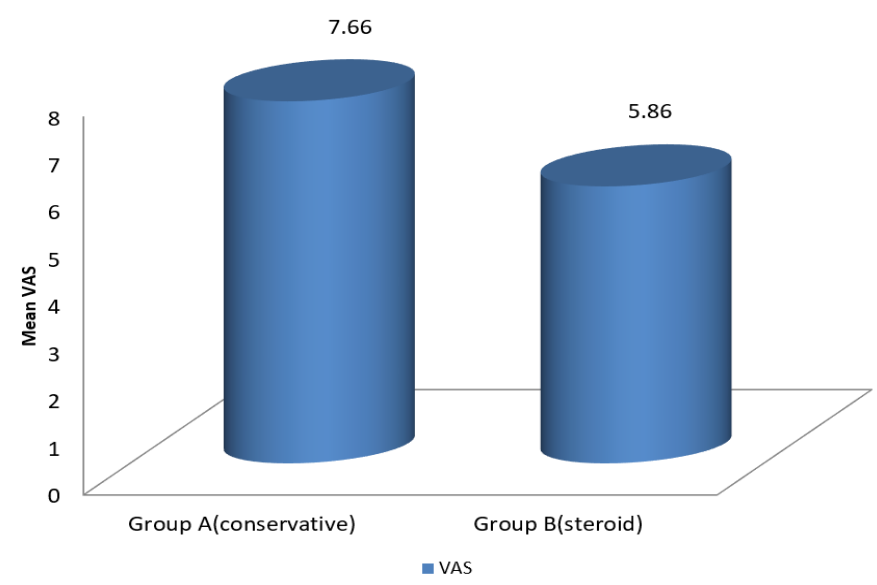

Graph III: Mean ODI among both groups

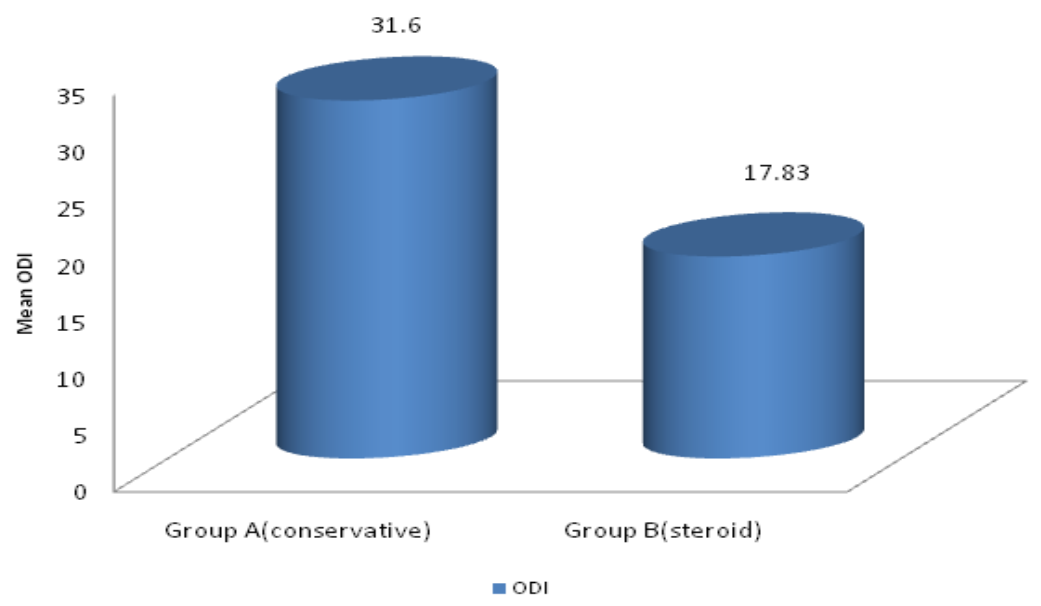


In the present study mean age of group A 42.40 with standard deviation of 10.09 and of group B 39.60 with standard deviation of 12.09 which was not statistically significant $(\mathrm{P}>0.334)$. In the present study baseline data of short form Mc gill pain questionnaire, Visual analogue Scale and Oswestry Low Back Pain and Disability Index homogenous among both groups (Table I). The pre and post comparison for outcome variables like Short form Mc gill pain questionnaire, Visual Analogue Scale and Oswestry Low Back Pain and Disability Index were statistically significant among both groups except for Short form Mc gill Pain Questionnaire in the group A which was not statistically significant (Table II \& III). However comparing between groups, all the outcome measures were reduced in group B compared to Group A which was statistically significant $(\mathrm{p}<.0001)$. So the results showed that group B was better than group A after three weeks of intervention (Table IV, Graph I,II,III)

\section{Discussion}

Myofascial Pain Syndrome is a very common cause of clinically observed local muscle pain, tenderness and referred pain in patients with acute and chronic pain. It is usually debilitating and influences every aspect of a patient's life. The objective of this study is to compare the clinical outcomes of local steroid infiltration with conservative management and conservative management alone in chronic low back pain due to Myofascial Pain syndrome.

In the present study, the majority of patients belonged to the age group greater than 30 years. The mean age of the patients in the conservative group was 42.40, and in the steroid group was 39.60. People in the active age group were seen to be maximally affected and this may point towards the great economic impact of Myofascial Pain Syndrome in our society. A Double-Blind (For Injection, Groups Only), Randomized Clinical Trial on Comparison of the Efficacy of Dry Needling, Lidocaine Injection, and Oral Flurbiprofen Treatments in Patients with
Myofascial Pain Syndrome which was published in Turk J Rheumatol 2013, showed that there were no significant differences between the groups in terms of age and gender ( $\mathrm{p}$ value $>0.05$ ).

When pain scores were measured by the SF McGill Pain Questionnaire and by the VAS, steroid infiltration combined with conservative management showed better results than those in the conservative management group at each of the follow-up visits, the scores being statistically significant.

Hong compared the efficiency of dry needling and lidocaine in patients with Myofascial Pain Syndrome in the upper trapezius muscle. Subjective pain severity was evaluated by VAS and pain was improved in both groups but difference between the groups were not significant after treatment. A Double-Blind (For Injection, Groups Only), Randomized Clinical Trial on Comparison of the Efficacy of Dry Needling, Lidocaine Injection, and Oral Flurbiprofen Treatments in Patients with Myofascial Pain Syndrome which was published in Turk J Rheumatol 2013 showed that VAS pain scores decreased and quality of life significantly improved in all the groups studied, but there were no significant differences found with regard to the efficacy of these treatments.

With regard to disability from low back pain, steroid infiltration combined with conservative management resulted in lesser disability scores as measured by the Oswestry Low Back Pain and Disability Index when compared with conservative management alone, at all the followup visits, each difference being statistically significant.

\section{Conclusion}

In this study it was found that local steroid injection of Myofascial Trigger Points combined with conservative management resulted in better pain relief and functional outcome in chronic low back pain due to Myofascial Pain Syndrome than conservative management alone. 


\section{Limitation}

1. For complete assessment of efficacy of treatments, patients have to be followed up over a longer time.

2. A large, double blind controlled clinical trial would be desirable

\section{References}

1. Physical Medicine And Rehabilitation, Randall L. Braddom

2. Chee Kean Chen, Abd Jalil Nizar, Myofascial Pain Syndrome in Chronic Back Pain Patients, Korean J Pain, 2011 Jun; 24(2): 100-104)

3. Gerwin RD, Shannon S, Hong C-Z, et al: Identification of myofascial trigger points: interrater agreement and effect of training, pain 69:65-73.

4. Simons DG, Travell JG, Simons LS: Travell \& Simons myofascial pain and dysfunction: the

trigger point manual, vol. 1, ed2, Baltimore, 1999, Williams \& Wilkins.

5. Malanga G, Wolff E Evidence-informed management of chronic low back pain with trigger point injections:Spine Journal in 2008Jan-Feb;8(1):243-52.doi:

10.1016/j.spinee.2007.10.029.

6. Iwama H, Akama $\mathrm{Y}$. The superiority of water diluted $0.25 \%$ to near $1 \%$ lidocaine for trigger point injections in myofascial pain syndrome: a prospective, randomized, double blinded trial. Anesth Analg 2000;91(2):408-409.

7. Xie P, Qin B, Yang F, Yu T, Yu J, Wang $\mathrm{J}$, Zheng $\mathrm{H}$;Lidocaine Injection in the Intramuscular Innervation Zone Can Effectively Treat Chronic Neck Pain Caused by MTrPs in the Trapezius Muscle:2015 Sep-Oct;18(5):E815-26.

8. Bonica's management of Pain by Scott M. Fishmen (editor), Jane C. Ballantyne (editor), James P. Rathmell (editor).
9. Mata Diz JB ${ }^{1}$, de Souza $\mathrm{JR}^{1}$, Leopoldino $\mathrm{AA}^{2}$, Oliveira $\mathrm{VC}^{3}$; Exercise, especially combined stretching and strengthening exe rcise, reduces myofascial pain a systematic review: J Physiother. 2017 Jan;63 (1):1722. doi: 10.1016/j.jphys.2016.11.008. Epub 2016 Dec 3.

10. Clara S. M. Wong, Steven H. S. Wong: A New Look at Trigger Point Injections; Anesthesiol Res Pract. 2012; 2012: 492452.2011 Sep 29.

11. Niraj $G^{1} ; \quad$ Pathophysiology and Management of Abdominal Myofascial Pain Syndrome (AMPS): A Three-Year Prospective Audit of a Management Pathway in 120 Patients;Pain Med. 2018 Feb 9. doi: 10.1093/pm/pnx343. 